\title{
SISTEM INFORMASI PEMESANAN MAKANAN DI RESTORAN XYZ DEPOK BERBASIS JAVA
}

\author{
Isfan Fahreza ${ }^{1}$, Senna Hendrian ${ }^{2}$, Intan Mutia ${ }^{3}$ \\ Program Studi Teknik Informatika, Fakultas Teknik dan Ilmu Komputer, \\ Universitas Indraprasta PGRI \\ Jalan Raya Tengah No 80, Kelurahan Gedong, Pasar Rebo, Jakarta Timur \\ fahreza1973@gmail.com ${ }^{1}$, senna.hendrian@gmail.com ${ }^{2}$, as_syifaraa@yahoo.comํㅗㄴ
}

\begin{abstract}
Abstrak
Di Indonesia, terdapat kegiatan yang belum dapat dikatakan efektif dan efisien dalam perkembangan teknologi ini. Pada industri kuliner khususnya restoran dimana kegiatan proses bisnis dalam pemesanan masih menggunakan cara yang manual. Pelanggan hanya ingin masuk ke restoran dan langsung menerima pesanan makanan yang sebelumnya telah dipesan tanpa harus menunggu lama sehingga diperlukannya sebuah sistem informasi yang dapat memenuhi permintaan tersebut. Tujuan Rancang Bangun Sistem Informasi Pemesanan Makanan Di Restoran XYZ Depok Berbasis Java adalah untuk mengelola sistem pemesanan makanan di restoran sehingga terlaksana lebih cepat, tepat dan efisien dan disimpan dengan baik dan aman dalam database. Metode penelitian ini adalah Grounded Research secara langsung, wawancara dengan pegawai, dan dokumentasi. Hasil dari penelitian ini adalah dibuat aplikasi sistem informasi pemesanan makanan berbasis Java dengan alat bantu perancangan sistem yaitu Diagram Alir Data (DAD) yang menggunakan bahasa pemrograman JAVA Netbeans 8.2, dan Database MySQL.
\end{abstract}

Kata Kunci: Sistem Informasi, Pemesanan, Pembayaran, Java, MySQL.

\begin{abstract}
In Indonesia, there are activities that cannot be said to be effective and efficient in the development of this technology. In the culinary industry, especially restaurants where business process activities in ordering still use manual methods. Customers just want to enter the restaurant and immediately receive food orders that have previously been ordered without having to wait long so that an information system is needed that can meet the request. The purpose of Designing Food Ordering Information System In Restaurant XYZ Depok Java-Based is to manage the food ordering system in restaurants so that it is carried out faster, precisely and efficiently and stored properly and securely in the database. This research method is grounded research in person, interviews with employees, and documentation. The result of this study was created a Java-based food ordering information system application with system design tools, namely Data Flow Diagram (DAD) which uses the JAVA Netbeans 8.2 programming language, and MySQL Database.
\end{abstract}

Keywords: Information Systems, Ordering, Payment, Java, MySQL.

\section{PENDAHULUAN}

Seiring dengan berkembangnya sistem informasi saat ini, "banyak informasi pada organisasi yang ingin mencapai tahap sistem informasi secara cepat, relevan dan akurat" (Tabrani, 2014). Namun tidak semua sistem informasi yang dibutuhkan, berjalan dengan baik dan sesuai dengan fungsi yang dibuat. "Pesatnya pertumbuhan Ilmu Pengetahuan Teknologi (IPTEK)" (Didik \& Hadi, 2019) khususnya dibidang komputer di setiap aspek kehidupan dalam penggunaan teknologi komputer dan teknologi komunikasi yang menghasilkan sebuah penggabungan sistem informasi yang saat ini menjadi lebih mudah diakses tanpa mengenal adanya batasan waktu dan jarak dengan menggunakan jaringan internet. Model penjualan atau bisnis juga ikut terpengaruh dari perkembangan IPTEK tersebut, terlebih dengan pesatnya pertumbuhan penggunaan internet di berbagai belahan dunia khususnya negara-negara berkembang "Salah satu bisnis yang menjadi trend baru dimasyarakat sekarang ini adalah dalam bidang pemesanan sehingga akan memberikan fasilitas dan pelayanan yang memuaskan terhadap pelanggan, untuk mewujudkan hal tersebut dibutuhkan kualitas pelayanan yang baik" (Saputri et al., 2019). 
Dalam mencapai tujuan tersebut tentu akan menghadapi sebuah permasalahan sehingga usaha dagang tersebut harus memperkuat strategi pelayanan dengan menetapkan suatu sistem pelayanan dengan menggunakan sistem manajemen pengolahan data yang baik dan benar agar dapat memperoleh hasil yang diinginkan, Sistem informasi berguna untuk menyediakan informasi manajemen dalam mengambil keputusan dan juga untuk menjalankan operasional perusahaan.Dimana sistem tersebut merupakan kombinasi dari manusia, "teknologi informasi dan prosedur-prosedur yang terorganisasi.dapat mempermudah dalam mengupdate informasi yang ada di Perusahaan serta dapat memberikan kesan Profesional karena kita tidak tertinggal dari segi kemajuan zaman, dan itu merupakan cara yang inovatif " (Dharmaadi \& Arya Sasmitha, 2018).

Di Indonesia, terdapat kegiatan yang belum dapat dikatakan efektif dan efisien dalam perkembangan teknologi ini. "Pada industri kuliner khususnya restoran dimana kegiatan proses bisnis dalam pemesanan masih menggunakan cara yang manual " (Ananda Putra \& Rahyuda, 2018). Pelanggan hanya ingin masuk ke restoran dan langsung menerima pesanan makanan yang sebelumnya telah dipesan tanpa harus menunggu lama sehingga diperlukannya sebuah sistem informasi yang dapat memenuhi permintaan tersebut. "Restoran XYZ adalah merupakan salah satu yang bergerak dalam bidang kuliner konsep dan sistem yang dipergunakan masih menggunakan cara yang manual " (Sancoko, 2015). Maka dari itu, dibutuhkan sebuah sistem informasi yaang membuat pelanggan dapat melakukan pemesanan makanan tanpa harus mengantri lama. Hal ini teruta makan akan sangat membantu untuk jenis restoran yang setiap waktunya memiliki antrian panjang, membiarkan pelanggan untuk menunggu adanya meja yang kosong. Dampak yang dapat dihasilkan antara lain bagi pemilik restoran yaitu dapat memaksimalkan proses bisnis yang terjadi di restoran karena telah meminimalisir masalah. Oleh karena itu, dibuatlah sistem informasi untuk pemesanan makanan yang bertujuan untuk menjadikan pelayanan lebih cepat dan mudah dan membangun sistem pendataan pemesanan menu makanan yang terkomputerisasi sehingga pengelolaan data lebih akurat dan efisien.

\section{PENELITIAN RELEVAN}

Dalam rangka mendapatkan hasil penelitian yang baik, selain melakukan penelitian secara langsung penelitian juga melakukan kegiatan pustaka.Dari hasil yang telah di lakukan. Beberapa hasil acuan adalah: Penelitian Oleh (Rizki Maulana \& Bunyamin, 2015) Yang berjudul " Rancang Bangun Sistem Informasi Penjualan dan Stok Barang di Toko Widari Garut “. Dengan hasil data yang dikumpulkan dapat disimpulkan system konvensional dengan pengolahan manual pada setiap transaksi yang di lakukan. Cara konvensional ini tidak efisien dan memungkinkan kesalahan dan kehilangan data lebih sering terjadi.Dengan adanya sistem komputerisasi yang diaplikasikan pada kion yulaika, kebutuhan pengguna dan proses data yang efektif dan efisien menjadi terpenuhi serta kehilangan dan kerusakan data pun dapat diminimalisir. Sistem Informasi Penjualan Roti Pada Home Industri Pitaloka Yogyakarta (Istikomah\&Pujiyono, 2013) Telah dibuat suatu sistem informasi penjualan roti akan berguna bagi pengguna dalam hal ini adalah pihak home industri pitaloka untuk memberikan kemudahan dalam transaksi penjualan roti. Telah dilakukan pengujian sistem informasi penjualan untuk dapat mengolah data penjualan roti dan dapat membuat laporan berguna bagi pengguna dalam hal ini adalah pihak home industri pitaloka.

\section{METODE PENELITIAN}

Metode penelitian dilakukan adalah dengan menggunakan metode grounded research dan metode observasi (pengamatan). Metode grounded research yaitu suatu metode penelitian yang berdasarkan fakta dangen tujuan dapat menetapkan konsep, mengembangkan teori, pengumpulan dan analisis data dalam waktu yang bersamaan.

Metode Pengumpulan Data dilakukan dengan observasi keterkaitan antara subsistem satu dengan yang lainnya dengan meninjau tentang pemilihan tabel dan menu restoran yang ada pada perusahaan tersebut,'(Febriyansyah et al., 2017) kemudian mengadakan pengamatan untuk memahami sistem berjalan terutama pada proses pelayanan restoran untuk mendapatkan kesimpulan-kesimpulan dari masalah-masalah yang bertujuan untuk perancangan sistem selanjutnya dan juga mendapatkan data dengan melakukan pengamatan langsung dengan sistem yang sedang berjalan, dengan pencatatan, dan pengumpulan data-data yang dilakukan pada 
Restoran XYZ Depok. Lalu dengan wawancara pada pelayan bagian pemesanan bernama Ashari Adhi Pratama, tentang bagaimana proses pelayanan restoran pada Restoran XYZ aliran data dan juga sistem yang berjalan saat ini dan apa saja yang di butuhkan dalam proses pelayanan restoran tersebut. Berikutnya dengan Studi Pustaka dengan mencari data melalui buku-buku, artikel dan dari internet yang berkaitan dengan penelitian.

\section{HASIL DAN PEMBAHASAN}

Dekomposisi Fungsi Sistem yang di usulkan

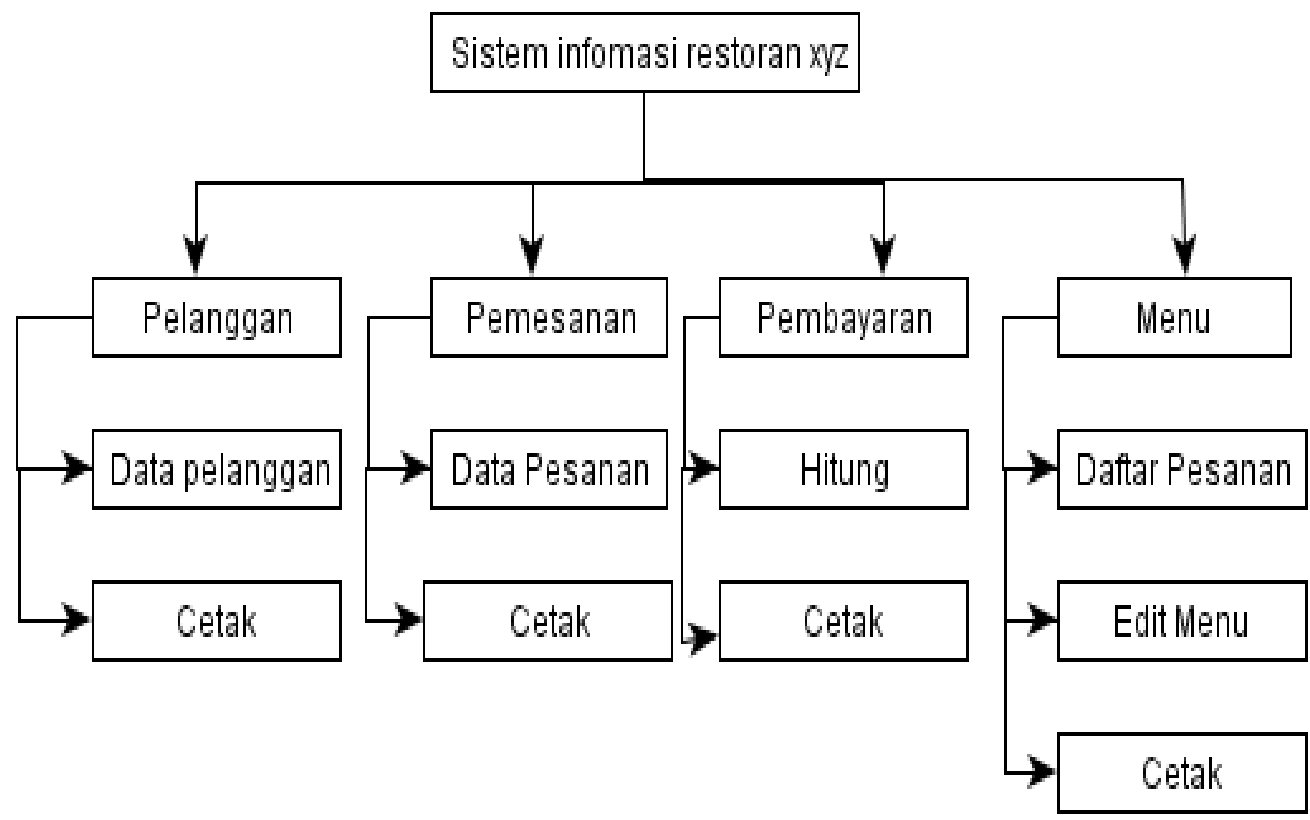

Gambar 1. Dekomposisi Fungsi Sistem yang Diusulkan

\section{Tampilan Menu Login}

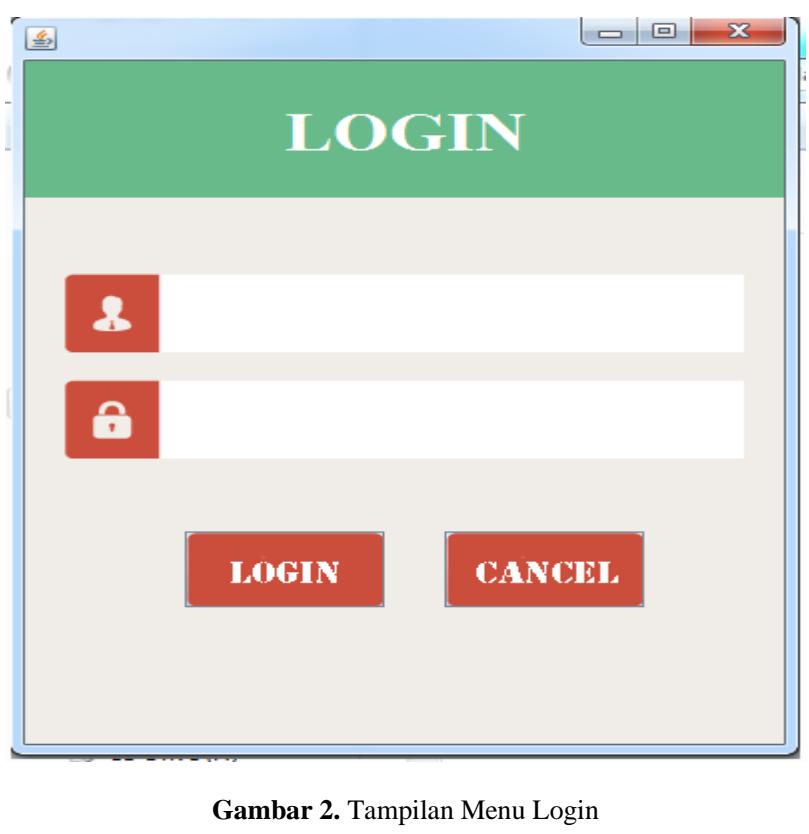


Form login digunakan sebagai akses memasuki ke menu utama. Agar tidak sembarangan orang dapat mengakses program ini pengguna diharuskan memasukan nama pengguna dan kata kunci dengan tepat kemudian klik login, maka menu utama akan tampil dan program siap dijalankan

\section{Tampilan Menu Utama}

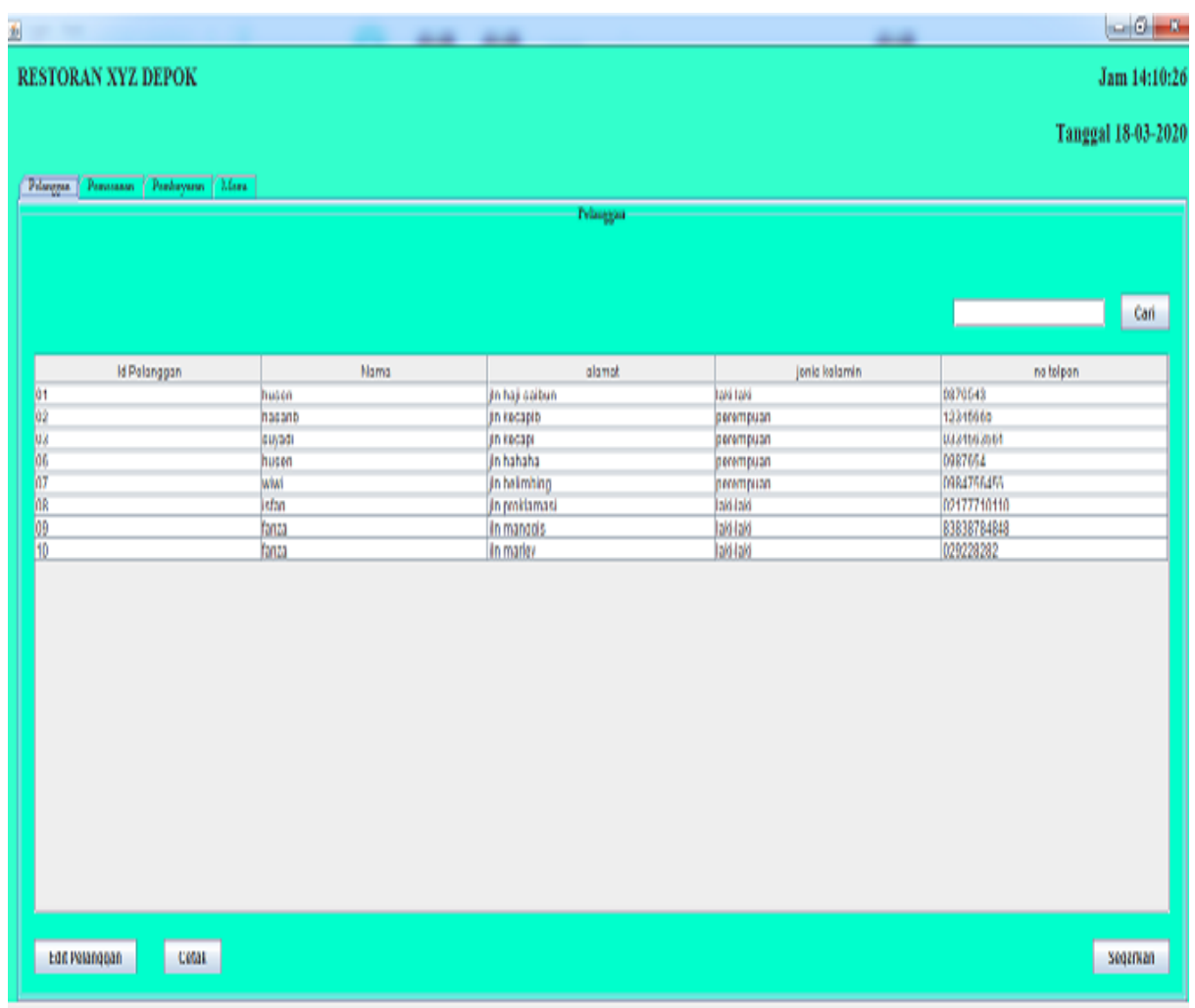

Gambar 3. Tampilan Menu Utama

Pada tampilan menu "Menu Utama" ini menampilkan form untuk ke tampilkan berikutnya. Admin dapat memilih menu Pelanggan, Pemesanan, Pembayaran, menu dan laporan untuk ke menu berikutnya. 


\section{Cetak Laporan}

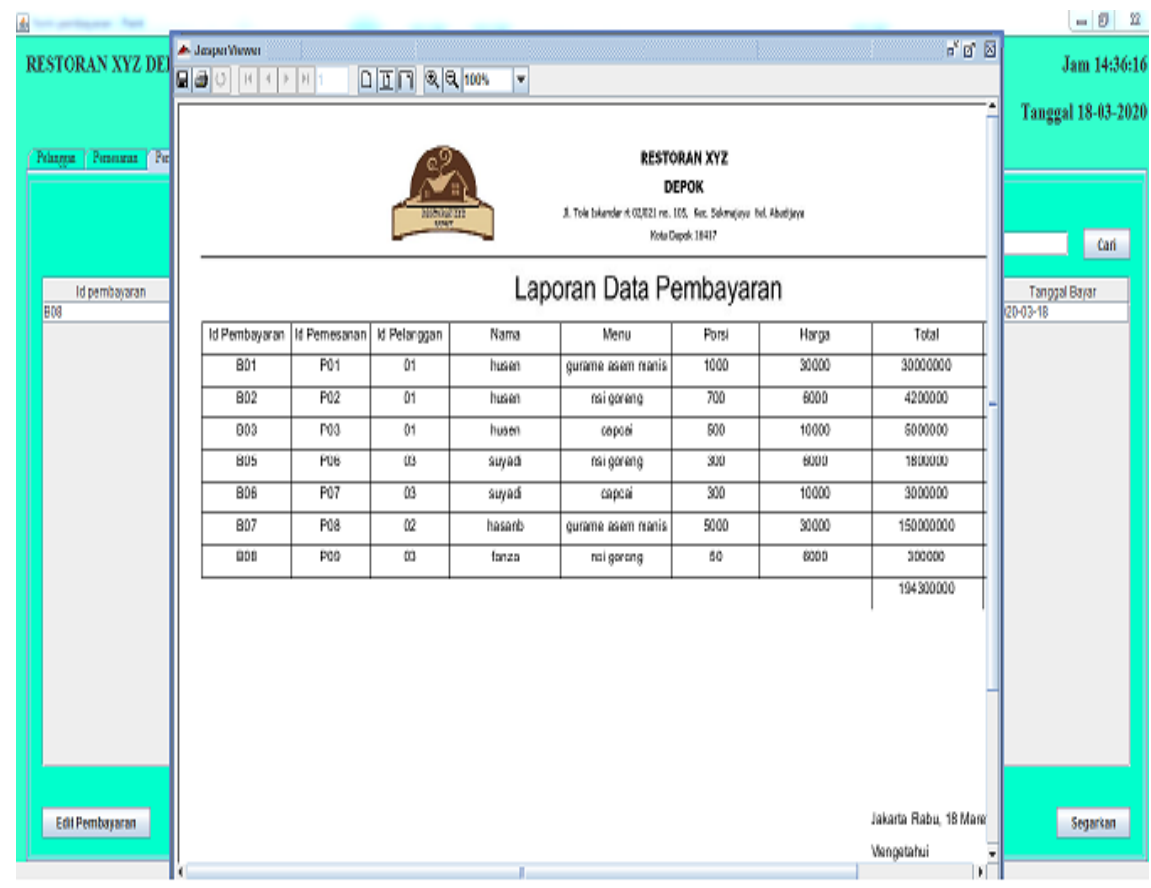

Gambar 4. Cetak Laporan

Hasil cetak report ini memperlihatkan pembayaran pesanan yang di pesan oleh pelanggan

\section{SIMPULAN}

Dengan dibuatnya sistem komputerisasi pada Restoran XYZ Depok, semua kegiatan yang berhubungan dengan pengelolahan data pemesanan, data menu, data pelanggan dan data laporan tidak lagi secara manual tetapi dengan menggunakan media berupa komputer. Pada sistem komputerisasi ini, sistem pendataan pemesanan yang berbasis komputer dapat menangani pekerjaan pegawai dengan cepat dan akurat serta dapat di up-date dengan mudah dan dengan adanya sistem ini diharapkan akan mempermudah kegiatan atau aktivas restoran dan masyarakat luas yang memerlukan kecepatan dan ketepatan informasi.

Berdasarkan pembahasan sebelumnya, maka dapat di simpulkan sebagai berikut:

1. Pengolahan data pemesanan menu makanan menjadi terorganisir dan terkomputerisasi.

2. Proses pendataan pemesanan menu makanan yang terkomputerisasi agar pendataan lebih cepat dan efisien.

3. Pengolahan data laporan dibuat dengan aplikasi berbasis Java agar laporan menjadi lebih akurat

\section{DAFTAR PUSTAKA}

Ananda Putra, I. M. Y., \& Rahyuda, K. (2018). Peran Perceived Value Memediasi Hubungan Kualitas Pelayanan Dengan Kepuasan Konsumen. E-Jurnal https://doi.org/10.24843/EJMUNUD.2018.v07.i05.p19

Dharmaadi, I. P. A., \& Arya Sasmitha, G. M. (2018). Perancangan Sistem Informasi Restoran Terintegrasi Berbasis Java Web Socket Online. Jurnal Penelitian Pos Dan Informatika. https://doi.org/10.17933/jppi.2018.080104

Didik, W., \& Hadi, A. P. (2019). Jurnal PIXEL diterbitkan oleh Sekolah Tinggi Elektronika dan Komputer (STEKOM). Jurnal PIXEL sebagai sarana komunikasi dan penyebarluasan hasil penelitian, pemikiran serta pengabdian pada masyarakat. Sistem Informarsi Akademi Dengan RFID Berbasis Sms Gateway (Studi Kasus Di Smk Muhhammadiyah 2 Boja). 
Febriyansyah, R., Negara, A. B. N., \& Safriadi, N. (2017). Rancang Bangun Aplikasi Pemesanan Menu Di Restoran Berbasis Web. Jurnal Sistem Dan Teknologi Informasi (JUSTIN).

Rizki Maulana, K., \& Bunyamin, H. (2015). Rancang Bangun Sistem Informasi Penjualan dan Stok Barang di Toko Widari Garut. Jurnal Algoritma. https://doi.org/10.33364/algoritma/v.12-1.119

Sancoko, A. H. (2015). Strategi Pengembangan Bisnis Usaha Makanan Dan Minuman Pada Depot Time To Eat Surabaya. Agora.

Saputri, Z. R., Oktavia, A. N., Ramdhani, L. S., \& Suherman, A. (2019). Rancang Bangun Sistem Informasi Pemesanan Makanan Berbasis Web Pada Cafe Surabiku. Jurnal Teknologi Dan Informasi. https://doi.org/10.34010/jati.v9i1.1378

Istikomah, Tri \& Wahyu Pujiyono. (2013). Sistem Informasi Penjualan Roti Pada Home Industri Pitaloka Yogyakarta. (2013). https://doi.org/10.12928/jstie.v1i2.2562

Tabrani, M. (2014). Implementasi Sistem Informasi Reservasi Penginapan pada Agrowisata Gunung Mas Cisarua Bogor. Bianglala Informatika. 